\title{
O DIREITO À SAÚDE NA CONSTITUIÇÃO BRASILEIRA: FERRAMENTAS DO SUS PARA ENFRENTAR A PANDEMIA DO SARS CoV2
}

\author{
Ana Paula Coelho Abreu dos Santos ${ }^{1}$ \\ William Picolo Fibrans ${ }^{2}$
}

Resumo: Aborda-se o tema do combate à Pandemia do SarsCoV2 no Brasil, tendo como filtro a Constituição Federal de 1988 e o Sistema Único de Saúde (SUS). Objetiva demonstrar a importância do SUS, analisar o papel das políticas públicas no enfrentamento da Atual Crise Sanitária, além de responder à problemática proposta. A pesquisa identificou a possibilidade de aplicar uma política pública capaz de controlar a Pandemia no âmbito brasileiro, obtendose eficácia pelos caminhos indicados ao decorrer do desenvolvimento e conclusão. Esta última, demonstrando o atendimento dos objetivos propostos, com solução para o problema apresentado.

Palavras-chave: Pandemia; Direito à Saúde; Políticas Públicas; Sistema Único de Saúde; Bem-estar.

\section{THE RIGHT TO HEALTH IN THE BRAZILIAN CONSTITUTION: SUS TOOLS TO FACE THE PANDEMIC OF SARS CoV2}

\begin{abstract}
The theme of combating the SarsCoV2 Pandemic in Brazil is approached, using the Federal Constitution of 1988 and the Unified Health System (UHS) as a filter. It aims to demonstrate the importance of the UHS, analyze the role of public policies in dealing with the Current Health Crisis, in addition to responding to the proposed problem. The research identified the possibility of applying a public policy capable of controlling the pandemic in the Brazilian context, obtaining effective ways indicated by the course of development and completion. The latter, demonstrating compliance with the proposed objectives, with solution to the problem presented.
\end{abstract}

Keywords: Pandemic; Right to health; Public policy; Unified Health System; Welfare.

\section{INTRODUÇÃO}

\footnotetext{
1* Mestra em Direito pela Faculdade Meridional IMED de Passo Fundo/RS, Especialista em Direito Constitucional pela Faculdade Damásio, Pós-Graduanda em Direito Ambiental pela Fundação ministério Público, Bacharel em Ciências Jurídicas e Sociais pela Universidade de Passo Fundo UPF, Advogada inscrita na OAB/RS 110.192, membro do Centro Brasileiro de Pesquisas sobre a Teoria da Justiça de Amartya Sen, ORCID: http://orcid.org/0000-0003-4730-4813, e-mail: anapcas@gmail.com, endereço postal: Rua Alfredo Chaves, n.으 075, Bairro Lucas Araújo, na Cidade de Passo Fundo/RS, CEP 99.074-270.

2* Mestrando em Direito pela Faculdade Meridional IMED, Taxista CAPES/PROSUP, Bacharel em Ciências Jurídicas e Sociais pela Faculdade Meridional IMED de Passo Fundo/RS, Advogado inscrito na OAB/RS sob o n.으 108.982, membro do Centro Brasileiro de Pesquisas sobre a Teoria da Justiça de Amartya Sen, ORCID: http://orcid.org/0000-0002-9564-2334, e-mail: williampf.adv@gmail.com, endereço postal: Rua Marquês de Caravelas, n.ํ 171, Bairro Santa Maria, na Cidade de Passo Fundo/RS, CEP 99.054-010.
} 
O presente estudo trabalha o tema do combate à Pandemia do SARS CoV2 no Brasil, de modo relacionado e limitado ao campo da Constituição Federal de 1988, legislações correlatas e do Sistema Único de Saúde (SUS), pelo que interessa ao desenvolvimento do mesmo, a estrutura das políticas públicas e o seu papel desempenhado, o que é analisado de forma intrínseca à problemática proposta.

Nesse condão, problematiza-se à cerca da possibilidade de aplicar uma política pública eficaz no controle da Pandemia, em âmbito brasileiro, e qual seria o caminho indicado.

O problema estudado tem a sua justificativa arguida na necessidade emergencial de se discutir, desenvolver, estudar e promover temas de combate à Pandemia causada pelo Novo Coronavírus, o que representa a produção de ideias capazes de garantir a manutenção da saúde e o salvamento de vidas das pessoas.

A análise do problema está em sintonia com diversos estudos desenvolvidos por órgãos internacionais, tais como a Organização Mundial da Saúde (OMS), com observância à dados divulgados por instituições de credibilidade, além da matriz bibliográfica que inclui importantes autores, como Amartya Sen, André Luiz Nakamura e José Afonso da Silva.

$\mathrm{O}$ presente artigo objetiva desenvolver conhecimentos úteis e seguros à respeito do tema, capazes de bem informar ao leitor, demonstrando a importância do SUS, bem como, analisar o papel das políticas públicas no enfrentamento da Atual Crise Sanitária, além de responder à problemática proposta.

\section{O DIREITO À SAÚDE NA CONSTITUIÇÃO BRASILEIRA}

O Direito à Saúde está positivado no artigo (art.) $6^{\circ}$ da Constituição Federal de 1988, sendo considerado, portanto, um direito social e fundamental de grande relevância.

Afinal, conforme definem Araujo e Júnior (2013), o direito à saúde é um desdobramento do direito à vida, de modo que seria incabível a sua desconsideração como um direito fundamental.

Em outras palavras, o direito fundamental à vida não trata apenas da garantia de não ser morto, e portanto, viver o curso natural da existência humana, mas sim, ter uma vida digna, no que se inclui viver com saúde e livre de altos riscos como por exemplo, a 
possibilidade de se contaminar com uma doença grave para a qual o Estado não ofereça prevenção, proteção e, ou, tratamento.

Nesse contexto, é importante o ensinamento trazido por Amartya Sen (2011, p. 260 261) quando da sua análise geral à respeito da liberdade, e de modo mais específico, da liberdade para "viver vidas razoavelmente longas (livre de doenças evitáveis e outras causas de morte prematura)", o que o mesmo afirma depender de muitos outros fatores além da renda elevada, destacando, entre outros, a organização social (o que inclui a saúde pública) e a garantia de assistência médica.

Nesse sentido, um país preocupado com a saúde e a vida da população não deve transferir a incumbência da garantia de tais direitos exclusivamente à instituições privadas, pois quem possui renda mais elevada, salvo situações excepcionais, poderá demandar serviços de saúde nessas instituições, contudo, a ausência da prestação pública deste serviço essencial representaria grave política de desigualdade social aplicada pelo Estado por meio de sua inércia.

Ao debater as liberdades substantivas para levar o tipo de vida que as pessoas teriam razão para valorizar, Sen (2010) determina que a pobreza deve ser vista como privação de capacidades básicas, e não como um problema menos latente como baixa renda.

Afinal, a pobreza pode representar, por exemplo, em um país menos assistencialista, a incapacidade de ter acesso à saúde preventiva, protetiva e, ou, combativa. Tal situação, conforme já desenvolvido, representa um risco social, com possibilidade agressão ao direito à vida.

Nesse sentido, resta evidente a imprescindibilidade da garantia do direito à saúde em uma Constituição cidadã, que reconheça o acesso a tal direito em seus aspectos universal e igualitário, estabelecendo ao Estado o dever de sua garantia. É nessa linha que Silva (2014, p. 844) conceitua o direito à saúde:

A saúde é concebida como direito de todos e dever do Estado, que a deve garantir mediante políticas sociais e econômicas que visem à redução do risco de doença e outros agravos. O Direito à saúde rege-se pelos princípios da universalidade e da igualdade de acesso às ações e serviços que a promovem, protegem e recuperam.

Sendo cristalino o dever do Estado em garantir o acesso à saúde, o mesmo estabeleceu mecanismos de atuação e gestão capazes de organizar, coordenar e cumprir com a 
incumbência constitucional, desde as regras próprias do art. 198 da Constituição Federal de 1988, àquelas definidas pela Lei número (n. $\left.{ }^{\circ}\right) 8.080$ de 1990, que instituiu o Sistema Único de Saúde (SUS), por exemplo.

Conforme ensinam Araujo e Júnior (2013), os serviços públicos importantes como aqueles relativos à saúde devem fazer parte de uma rede regionalizada, com hierarquia, e constituir um sistema único. Na Constituição Brasileira de 1988, foi preconizado um regime de cooperação entre os entes federativos, com a finalidade de incrementar o atendimento à saúde da população. Trata-se de um agir solidário, complementar e descentralizado.

O acima definido possibilita por parte da população a busca pelo atendimento à saúde de forma mais acessível, pois tanto a União, como Estados e Municípios podem ser exigidos e demandados pela prestação de serviços e ações relativas à saúde. Da mesma forma, seus aspectos de universalidade e igualdade indicam que qualquer pessoa que resida no país tem o direito a ser atendido pela rede pública de saúde livre de qualquer diferenciação.

Esse acesso atende à relevância do direito à saúde, que afinal, é um direito de segunda geração de tal imprescindibilidade que o Constituinte obrigou os entes federativos à aplicar percentuais mínimos de orçamento, inclusive, prevendo pena de intervenção federal nos estados, e destes nos municípios (NAKAMURA, 2016).

A garantia da aplicação de tais percentuais obrigatórios por parte dos entes federativos é de fundamental importância prática, pois se tratando de um direito de segunda geração, o mesmo necessita de recursos para sua implementação, de modo que deve haver uma progressão para que o direito à saúde não esbarre na ausência de recursos públicos.

Em sentido contrário, porém, em 15 de dezembro de 2016, o Brasil promulgou a Emenda Constitucional (EC) número 95 (noventa e cinco), conhecida como lei "do teto de gastos" (G1, 2021). A legislação prevê o congelamento de investimento nas áreas da educação e da saúde por 20 (vinte) exercícios financeiros, isto é, 20 (vinte) anos (BRASIL, 2016).

A medida representa um retrocesso para a história evolutiva do direito social brasileiro, que após décadas de expansão da proteção à saúde (sem sequer abordar os impactos na educação), passa a ser barrada pela referida Emenda Constitucional, a qual ignora a necessária progressão de investimentos para a implementação do direito à saúde.

Nesse sentido, o Conselho Nacional de Saúde (2021) apresentou dados alarmantes à cerca dos impactos da EC 95, tanto para o ano de 2019, bem como, fazendo uma projeção para os anos seguintes, conforme se elenca: 
Desde que a Emenda Constitucional (EC) 95 foi aprovada, em dezembro de 2016, o orçamento para a Saúde tem diminuído cada vez mais. Somente em 2019, a perda de investimentos na área representou $\mathrm{R} \$ 20$ bilhões, o que significa, na prática, a desvinculação do gasto mínimo de $15 \%$ da receita da União com a Saúde. [...]. "Com o orçamento congelado por 20 anos, o prejuízo ao Sistema Único de Saúde pode ultrapassar R\$ 400 bilhões", afirma o presidente do Conselho Nacional de Saúde (CNS), Fernando Pigatto, com base em estudo elaborado pela Comissão Intersetorial de Orçamento e Financiamento (Cofin) do CNS. "Ou seja, o SUS, que nunca teve financiamento adequado e sempre foi subfinanciado, agora enfrenta um quadro ainda pior, de desfinanciamento, que poderá causar grave impacto à vida e à saúde da população brasileira", completa.

Os dados acima citados são objetivos. Somente para o ano de 2019, R\$ 20.000.000.000,00 (vinte bilhões de reais) deixaram de ser investidos na saúde. A sociedade brasileira passa então a adquirir maior vulnerabilidade conforme o passar dos anos, afinal, o estudo também aponta um envelhecimento populacional para os próximos anos que por si exigirá um investimento adicional de R \$ 50,7 bilhões de reais em saúde até 2027 (Conselho Nacional de Saúde, 2021).

É necessário estudar todos os pilares de sustentação da Previdência Social Brasileira, e ainda mais necessário conhecer e trabalhar com o terreno sob o qual tais pilares se erguem. Nessa reflexão sobre o fortalecimento da proteção do Direito à Saúde, importa retomar alguns passos no sentido de seu maior financiamento.

Assim, é imprescindível ater-se que o Brasil é signatário do Pacto Internacional de Direitos Econômicos, Sociais e Culturais (Decreto n. ${ }^{\circ}$ 591, de 06 de julho de 1992), com força de Emenda Constitucional, sendo obrigado, tal como outros Estados Parte, a adotar medidas que garantam o pleno exercício dos direitos reconhecidos no Pacto, dentre eles, o direito à saúde, conforme se observa:

Cada Estado Parte do presente Pacto compromete-se a adotar medidas, tanto por esforço próprio como pela assistência e cooperação internacionais, principalmente nos planos econômico e técnico, até o máximo de seus recursos disponíveis, que visem a assegurar, progressivamente, por todos os meios apropriados, o pleno exercício dos direitos reconhecidos no presente Pacto, incluindo, em particular, a adoção de medidas legislativas (brasil, 1992).

Para que o Pacto seja cumprido, torna-se salutar objetivar a formulação de política de saúde e assistência capaz de promover, prevenir, proteger e recuperar a saúde da população, o 
que é possível por meio de um sistema unificado fortalecido, cuja função desempenhada seja aplaudida por representantes de governo, com a busca por melhoras constantes neste sistema.

Se tratando da realidade brasileira, a Lei n. ${ }^{\circ} 8.080$ de 19 de setembro de 1990 instituiu o Sistema Único de Saúde (SUS), com a finalidade de regular as ações e serviços de saúde por todo o território nacional. Conforme dispõe o art. $5^{\circ}$ da referida norma, entre os objetivos do SUS, está a formulação de políticas de saúde que se destinem a reduzir o risco de doenças e outros agravos, bem como, estabelecer condições que garantam a eficácia dos princípios da universalidade e igualdade no exercício de ações que busquem a promoção, proteção e recuperação da saúde das pessoas (BRASIL, 1990).

Ora, é certa a importância de uma política pública como o SUS no enfrentamento de pandemias e epidemias, pois este atua em todo o território nacional, com livre acesso por toda a população, de forma gratuita.

\section{SARS COV2 - LINHA EVOLUTIVA E ASPECTOS DE BEM-ESTAR}

\section{EM AMARTYA SEN}

Ao estudar temas relacionados com o SARS CoV2 ${ }^{3}$, torna-se imprescindível abordar a evolução cronológica do vírus, ainda que de forma simplificada, pois este avançou de forma agressiva pelo planeta, exigindo ações precoces, sérias e competentes por parte de governos.

É importante recordar que ainda em dezembro de 2019, era descoberto o primeiro caso do vírus em Wuhan, na China, e em pouco tempo se desencadeou uma corrida global de estudos para o combate e prevenção da doença para a qual ainda restam muitas dúvidas acerca de sua origem, conforme estudos divulgados pela OMS (G1, 2021).

Conforme elucida a Organização Panamericana da Saúde (OPAS, 2020), durante este percurso, no dia 30 de janeiro de 2020, o SARS CoV2 foi declarado pela OMS como uma emergência de saúde pública de importância internacional, para em apenas dois meses depois, na data de 11 de março do mesmo ano, ser caracterizado como uma pandemia.

\footnotetext{
${ }^{3}$ Sars, sigla para Síndrome Respiratória Aguda Grave, que assolou a China no início dos anos 2000, mas foi contida, é provocada por um coronavírus, o SARS-CoV-1. E é um "parente" dele que causa a Covid-1, batizado de SARS - CoV -2 (VEJA, 2020).
} 
Esta rápida contaminação pelo vírus, espelhando-se por diversos países e continentes causou importante impacto no cotidiano mundial, impondo diversas restrições de convivência social, liberdade de ir e vir, dentre outras.

A disseminação da COVID-19 causou mais de cinquenta mil casos e três mil mortes, o que levou a localidade a entrar em lockdown - bloqueio total - por mais de dois meses. Em maio de 2020, quando a China voltava a registrar um leve aumento no número de casos, estabilizando o número de mortes em cerca de oitenta e duas mil, o Brasil já ultrapassava a marca de dez mil mortes (PODER 360, 2020).

Da referida situação vivenciada pela China, poder-se-ia retirar uma importante lição. Ora, se com as medidas rigorosas adotadas pelo país, tal como o lockdown, a mesma atingiu a marca de mais de oitenta mil vítimas fatais em cerca de seis meses, quantas pessoas poderiam se tornar vítimas fatais em países que não encarassem a Pandemia com a devida seriedade e comprometimento.

Entretanto, o governo brasileiro não realizou tal questionamento, superando as expectativas mais pessimistas no combate à Pandemia, sendo que na data de 30 de março de 2021, o País foi confirmado como líder em número de morte pela COVID-19 no mundo, para o mês de março $(\mathrm{G} 1,2021)$. Ainda, na data seguinte, registrou quase quatro mil mortes diárias pelo vírus, fechando o pior mês no combate à Pandemia, com sessenta e seis mil e oitocentos óbitos, contabilizando quase treze milhões de casos, com trezentos e vinte e um mil e oitocentos e oitenta e seis óbitos $(\mathrm{G} 1,2021)$.

Os dados mais recentes obtidos pelo presente estudo registram 19.389.167 (dezenove milhões e trezentos e noventa e nove mil cento e sessenta e sete) casos de coronavírus, com 542.877 (quinhentos e quarenta e dois mil e oitocentos e setenta e sete) óbitos, momento em que o Estado de São Paulo se tornou o primeiro a atingir o percentual de 50\% (cinquenta por cento) de sua população vacinada com a primeira dose de vacina contra o SARS CoV2 (G1, 2021).

Conforme já estudado, o Brasil dispõe do SUS, um sistema capaz de atuar com ampla cobertura no combate e prevenção de epidemias e outros agravos. A disposição de tal ferramenta à mão do governo indaga à respeito de como foi possível o País chegar à tais números.

Afinal, conforme explana Da Silva (2014, p. 844), “[...]. O sistema único de saúde implica ações e serviços federais, estaduais, distritais (DF) e municipais [...], com prioridade 
para as atividades preventivas". "A direção única em cada esfera de governo revela que o SUS tem como gestor federal o Ministro da Saúde [...]” (ARAUJO; JÚNIOR, 2013).

A atuação descentralizada do SUS, ainda mais após aprovação da Medida Provisória n. ${ }^{\circ}$ 926, de 20 de março de 2020, convertida na Lei n. ${ }^{\circ} 14.035$ de 11 de agosto de 2020, que autorizou a definição de políticas de enfrentamento à Pandemia por parte de autoridades estatais e municipais, facilitando a tomada de medidas precisas de acordo com a realidade vivenciada por cada localidade (BRASIL, 2020), deveria representar um passo à frente no combate ao Coronavírus. Ocorre que esta segunda medida legislativa foi tomada em razão grave problema de cunho político (visões políticas) ocasionado pelo governo federal ao questionar políticas (ações) de confinamento e prevenção da transmissão da COVID-19 tomadas pelo então Ministro da Saúde, Nelson Teich, o que provocou o pedido de demissão deste último (PODER 360, 2020).

A ausência de um Ministro da Saúde durante o período de pandemia, portanto, acabou criando uma enorme lacuna na gestão federal do SUS, por mais que o secretárioexecutivo da pasta, Eduardo Pazuello, tenha assumido o cargo interinamente

O Brasil chegou a registrar mais de cento e quinze mil mortos pelo SARS CoV2, e ainda assim, se completavam cem dias sem um Ministro da Saúde para substituir o nome de Nelson Teich. Somado à dissidia governamental na escolha de um Ministro competente capaz de exercer o cargo no momento pandêmico, o Presidente da República incentivou aglomerações, minimizou a COVID-19, e até mesmo ridicularizou mortes (REDEBRASILATUAL, 2020).

Neste sentido, resta preciso que o Brasil possui mecanismos de enfrentamento à Pandemia gerada pelo SARS CoV2, seja através do SUS, medidas legislativas, dentre outros.

Contudo, deve-se tomar vital atenção para os interesses envolvidos por trás das políticas governamentais de atuação diária, afinal, como um Estado de bem-estar social que acredita-se enquadrar o Brasil, este deve-se buscar atender aos interesses e valores essenciais dos indivíduos que compõe a sociedade, e não de seus governantes enquanto sujeitos isolados (SEN, 2017).

Nesse sentido, é imprescindível nos atentarmos para a discussão e estudo de políticas públicas, o que será trabalhado no próximo capítulo, objetivando, dentre outros fins, relacionar e fundamentar a sua importância no combate à Pandemia. 


\section{O PAPEL DO JUDICIÁRIO PARA GARANTIR O DIREITO SOCIAL Á} SAÚDE

A Covid-19 se transformou em uma realidade global, mas cada país dentro de sua soberania busca se adequar e enfrentar essa realidade, sendo que políticas eficazes de enfrentamento a essa mazela se tornam imprescindíveis, em que os direitos sociais, em específico, o direito à saúde, ganharam contornos emergenciais.

Dessa forma, se torna cabível a análise das estruturas das políticas públicas, de quem é o protagonismo de sua realização e o papel que essas devem desempenhar no presente cenário emergencial que a sociedade se encontra.

Nesse sentido, o adjetivo 'pública' refere-se ao protagonismo do agente primário da ação: o governo. Então, o fato de se tratar de política pública tem como pressuposto a execução ser realizada pelo governo, em que se entende governo como o corpo político que é responsável pela trajetória de determinado Estado (REISMAN; TONI, 2017).

Quanto à estruturação das políticas públicas, é cabível salientar as fases das políticas públicas, para Eduardo Appio (2012), existem três momentos, a fase da formulação das políticas públicas, a fase da execução e a fase da avaliação, na qual nessa última fase é mais costumeiro estar presente a intervenção do judiciário, por meio do controle de legalidade e legitimidade dos atos administrativos, especialmente por meio da Lei n. 8.429/1992 (Lei de Improbidade administrativas), bem como por meio de instrumentos correlatos ao controle exercido pelo Congresso Nacional, com o auxílio do Tribunal de Contas, visando assegurar a credibilidade da política pública.

Todavia, Schmidt (2008), sugere a existência de cinco fases das políticas públicas, são elas a fase de percepção e definição de problemas, o transformando em um problema político; a segunda fase seria de inserção na agenda política, podendo ser conceituado como um rol de questões relevantes debatidas pelos agentes públicos e sociais, com forte repercussão na opinião pública, ainda pode-se distinguir em três tipos de agenda política: a agenda sistêmica (assuntos que preocupam a sociedade, mas não está obtendo atenção do governo); Agenda governamental ou institucional (são os problemas que estão merecendo atenção do governo); Agenda de decisão (são os problemas em fase de decisão) (SCHMIDT apud VIANA, 2008). 
Posteriormente, Schmidt (2008) reconhece a fase de formulação, implementação e avaliação, de forma semelhante ao autor Eduardo Appio (2012), sendo que para aquele a fase de formulação consiste no momento de definir a maneira de solucionar o problema político em pauta, essa fase se processa, via de regra, na esfera do poder Legislativo e do Executivo. Já a fase da implementação diz respeito em concretizar o que foi formulado na fase anterior, está predominantemente a encargo do aparelho burocrático (administração). Por fim, a fase de avaliação, essa é vista pelo autor como um instrumento democrático, pois aos cidadãos também cabe avaliar a qualidade dos governos. A avaliação da política consiste em fazer um balanço dos êxitos e das falhas do processo de sua implementação (SCHMIDT, 2008).

Nesse prisma atentar-se para as políticas públicas voltadas à saúde, deve-se primeiro salientar o fato do direito à saúde ser um direito social, sua inserção está no art. $6^{\circ}$ da Constituição Federal Brasileira, ainda por se tratar de um direito social, também é denominado de direito fundamental de segunda geração ou dimensão, o qual exige uma atuação estatal. Logo, acentua-se a questão da eficácia da saúde em face do Estado, como pontua Nakamura (2016, p. 20): “[...] não existe direito absoluto a todo e qualquer procedimento na área da saúde sem uma política pública que o concretize. Há o direito a uma política pública eficiente e adequada que pode ser exercido contra o Estado, em caso de falha e ineficiência deste".

Ainda, destaca-se o fato do direito à saúde ser instrumento de outro direito fundamental, o direito à vida, logo, se o direito à saúde não for assegurado, a vida é colocada em risco, dessa forma a Constituição Federal em seu artigo 196 disciplina:

A saúde é direito de todos e dever do Estado, garantido mediante políticas sociais e econômicas que visem à redução do risco de doença e de outros agravos e ao acesso universal e igualitário às ações e serviços para sua promoção, proteção e recuperação (BRASIL, 1988).

Nesse sentido, o Brasil legisla na Constituição Federal de 1988, em matéria específica sobre a saúde, do artigo 196 ao artigo 200, sendo que há o caráter solidário, universal e igualitário presente nesses textos. Solidário, uma vez que o Sistema Único de Saúde (SUS), composto por um conjunto de órgãos integrados tem como função a promoção de atividades públicas de saúde, em todas as unidades da federação, em que os seus usuários não precisam ser contribuintes dos tributos que o custeiam, ou seja, não há contraprestação, conforme art.198, par. $1^{\circ}$, da Constituição Federal. 
Tem caráter de igualdade e universalidade, ao passo que há uma universalidade no atendimento, ou seja, abrange todas as pessoas tanto brasileiras quanto estrangeiras, ainda as ações públicas voltadas à saúde devem abranger todos os males, visando não somente a cura, mas também a prevenção, conforme preceito do artigo 194, inciso I, da CF, sobre aspectos da seguridade social.

De uma forma geral cabe destacar:

As políticas públicas têm distintos suportes legais. Podem ser expressas em disposições constitucionais, ou em leis, ou ainda em normas infra legais, como decretos e portarias e até mesmo em instrumentos jurídicos de outras naturezas, como contratos de concessão de serviço público, por exemplo (BUCCI, 2006, p.11).

Como visto a política pública de tipo reguladora, não necessariamente está prevista na Constituição ou em Lei, podendo encontrar-se em decretos, portarias ou contratos de concessão de algum serviço público, ou seja, as políticas públicas podem ser instituídas tanto por leis quanto por atos normativos.

Todavia, enquadra-se nas políticas com suporte legal a Lei n. ${ }^{\circ} 8.080 / 1990$, a qual organiza o funcionamento do SUS. Dessa forma, essa legislação possui elementos como princípios, objetivos, instrumentos e diretrizes que direciona a promoção da atividade pública de proteção à saúde, em todas as unidades da federação.

Dessa forma, entende-se que as políticas públicas são a materialização, a concretização da política, sendo o que o governo faz ou deixa de fazer, uma vez que as políticas públicas são, também, o que o governo deixa de fazer, sua ausência decisória, pois o não decidir é uma decisão a qual produz efeitos (RESMAN; TONI, 2017).

No caso dos direitos sociais há a exigência de uma postura ativa do Estado e no caso de omissões injustificadas de políticas públicas voltadas à saúde, pode se tornar objeto do controle judicial, como pontua Nakamura (2016, p.21):

\begin{abstract}
A implementação de direitos sociais implica na distribuição de recursos orçamentários. A forma como devem ser implementadas políticas públicas devem ser decididas pelo Poder Executivo, sendo a judicialização das políticas públicas uma exceção. Entretanto, como as normas de direitos fundamentais não são normas programáticas, a política pública pode ser objeto de controle judicial, em caso de omissões injustificadas que ocasionem a ineficácia do direito social.
\end{abstract}

Assim, aponta o autor que as políticas públicas devem ser implementadas pelo Poder Executivo, sendo a judicialização das políticas públicas uma exceção. Ressalte-se que, “[...] o controle judicial de políticas públicas emerge no interior de uma sociedade fragmentada pelas 
desigualdades sociais e marcada pela limitação decisória imposta por mecanismos tradicionais de representação do Estado" (APPIO, 2012, p. 137).

Essas limitações, conforme aponta Appio (2012), tem levado os gestores públicos a um dilema que consiste em priorizar diversos setores da economia, fazendo do Estado mero supervisor - e não agente - do desenvolvimento do país, resultando em um modelo de Estado neoliberal. Ou, por outro lado, buscar a justiça social.

Dessa forma o protagonismo do judiciário ganha espaço, protagonismo esse que é duramente criticado, uma vez que estaria invadindo a competência dos poderes executivo e legislativo, por exemplo. No entanto, a partir do momento em que há uma política já implementada como o direito à saúde, o direito à vida, bem como uma lei específica que regulamenta o Sistema Único de Saúde (Lei n. 8.080/1990), ainda, tendo em vista que diz respeito a um direito fundamental, sendo que há uma natureza coletiva, o direito deve ser protegido pelo Poder Judiciário.

Diante disso, ao frisar o atual cenário que enfrenta o mundo e o Brasil, frente à pandemia causada pelo coronavírus, o Poder Judiciário legitimou a Medida Provisória n. 926, de 20 de março de 2020, alterando o artigo $3^{\circ}$ e incisos I, II e IV, e parágrafos $8^{\circ}, 9^{\circ}, 10$ e 11 , da Lei Federal n. 13.979, de fevereiro de 2020, em que o Distrito Federal e os Municípios possuem competência para legislar sobre a saúde pública, podendo exercer as seguinte medidas de isolamento, quarentena e restrições com base em recomendações técnicas e fundamentada pela Agência Nacional de Vigilância Sanitária. Essa decisão foi confirmada com base no art. 23, inciso II, da CF, por nesse texto afirmar a competência comum da União, Estados, Distrito Federal e município para legislar sobre saúde pública.

Ainda, o Supremo Tribunal Federal formou maioria, em 23 de fevereiro de 2021, para permitir que estados e municípios comprem e distribuam vacinas contra a Covid-19, ou caso a União não forneça imunizantes o suficiente, tais medidas que possibilitam a atuação conjunta de autoridades estaduais e municipais para o enfrentamento dessa emergência de saúde pública, tem como condão suprir lacunas e omissões do governo central (CORREIO BRAZILIENSE, 2021).

Portanto, o direito à saúde como um direito fundamental de segunda geração, bem como este sendo um instrumento de proteção do direito fundamental à vida, leva a incumbência do Poder Executivo de implementar políticas que visem a sua consecução, ou seja, exige uma ação ativa do Estado, entretanto, frente a omissões injustificadas que 
ocasionem a ineficácia desse direito social o controle judicial dessas políticas deve ser exercido como forma de proteção individual e coletiva.

\section{CONCLUSÃO}

O presente artigo abordou o tema do combate à Pandemia do SARS CoV2 no Brasil, analisando a Constituição da República Federativa do Brasil de 1988, estabelecendo relações com legislações específicas, tal como a Lei n. ${ }^{\circ} 8.080$ de 1990, que instituiu o Sistema Único de Saúde (SUS).

Nesse aspecto, foi identificado e estruturado o direito fundamental à saúde, com importe bibliográfico, demonstrando o papel desempenhado pelo SUS na prevenção, proteção e recuperação de doenças e outros agravos, sendo regido pelos princípios da universalidade e igualdade, bem como, regidos em descentralização e solidariedade.

Igualmente, restou clara a gravidade global provocada pelo SARS CoV2, que impôs mudanças de hábito à nível global, ceifando a vida de milhares de pessoas por todo o mundo, e especialmente, no âmbito brasileiro, de mais de quinhentas e quarenta e duas mil pessoas.

Ainda, desenvolveu-se a temática das políticas públicas, sua estruturação e o protagonismo de quem deve formular e executar tais políticas, bem como, o papel do poder judiciário na sua fiscalização.

O problema foi respondido positivamente, no sentido da possibilidade de empregar uma política pública eficaz no controle da Pandemia, quer seja, a aplicação total da Lei n. ${ }^{\circ}$ 8.080 de 1990, para viabilizar a prevenção, combate e recuperação de pessoas acometidas ou sujeitas à contaminação pela COVID-19, com atenção especial para a vacinação da população brasileira. Ainda, sendo este o caminho indicado, o mesmo detém uma possibilidade de desdobramento, no caso da omissão ou ineficácia das políticas voltadas ao direito à saúde, que repousa na atuação do Poder Judiciário no ato de fiscalização da norma.

Da mesma forma, consideram-se atendidos os objetivos do presente artigo, em trazer informações de confiabilidade, relevância e concretude, demonstrando a importância do SUS no combate à doenças, epidemias, e principalmente, à Pandemia do CONVID-19, bem como, por meio da análise e comprovação da eficácia das políticas públicas no enfrentamento da referida Crise Sanitária, por meio dos instrumentos articulados. 


\section{REFERÊNCIAS}

APPIO, Eduardo. Controle Judicial das Políticas Públicas no Brasil. Curitiba: Juruá, 2012.

ARAUJO, Luiz Alberto David; JÚNIOR, Vidal Serrano Nunes. CURSO DE DIREITO CONSTITUCIONAL. 17 ${ }^{\mathrm{a}}$ Ed. São Paulo: Editora Verbatim, 2013.

BRASIL. Constituição Federal de 1988. Disponível em: <http://www.planalto.gov.br/ccivil_03/constituicao/constituicao.htm> Acesso em 31/03/2021.

BRASIL. Decreto n. ${ }^{\circ} 591$ de 06 de julho de 1992. Presidente da República. Disponível em: <http://www.planalto.gov.br/ccivil_03/decreto/1990-

1994/d0591.htm\#: :text=Bras\%C3\%ADlia\%2C\%2006\%20de\%20julho\%20de,e $\% 20104 \%$ C2 $\%$ B0\%20da\%20Rep\%C3\%BAblica.\&text=1.,desenvolvimento\%20econ\%C3\%B4mico\%2C $\% 20$ social\%20e\%20cultural.> Acesso: 30 de março de 2021.

BRASIL. Emenda Constitucional $n^{\circ}$ 95, de 15 de dezembro de 2016. Congresso Nacional. Disponível em: <http://www.planalto.gov.br/ccivil_03/constituicao/emendas/emc/emc95.htm> Acesso em: 20/07/2021.

BRASIL. Lei n. ${ }^{\circ}$ 14.035, de 11 de Agosto de 2020. Congresso Nacional. Disponível em: <http://www.planalto.gov.br/ccivil_03/_ato2019-2022/2020/Lei/L14035.htm> Acesso: 30 de março de 2021.

BRASIL. Lei n. ${ }^{\circ} 8.080$ de 19 de setembro de 1990. Congresso Nacional. Disponível em: <http://www.planalto.gov.br/ccivil_03/leis/18080.htm> Acesso em 30 de março de 2021.

BRASIL. Supremo Tribunal Federal. Ministro explicita competência de estados e municípios no combate ao coronavírus. 24 de mar. de 2020. Disponível em: $<$ http://portal.stf.jus.br/noticias/verNoticiaDetalhe.asp?idConteudo=440055\&ori=1> Acesso em: 31 de março de 2021.

BUCCI, Maria Paula Dallari. O conceito de política pública em direito. In: BUCCI, Maria Paula Dallari (Org.). Políticas Públicas: reflexões sobre o conceito jurídico. São Paulo: Saraiva, 2006.

CNN BRASIL. Disponível em: <https://www.cnnbrasil.com.br/saude/2021/03/30/brasil-e-opais-que-mais-registra-mortes-diarias-por-covid-19-em-marco > Acesso em 30 de março de 2021.

Conselho Nacional de Saúde. Ministério da Saúde. Disponível em: <http://www.conselho.saude.gov.br/ultimas-noticias-cns/1044-saude-perdeu-r-20-bilhoes-em2019-por-causa-da-ec-95 
2016\#: :text=Conselho\%20Nacional\%20de\%20Sa\%C3\%BAde\%20\%2D\%20Sa\%C3\%BAde, causa\%20da\%20EC\%2095\%2F2016> Acesso em: 20/07/2021.

CORREIO BRAZILIENSE. Estados e municípios podem comprar vacinas contra covid19, decide STF. 23 de fev. de 2021. Disponível em:

<https://www.correiobraziliense.com.br/brasil/2021/02/4908353-estados-e-municipios-

podem-comprar-vacinas-contra-covid-19-decide-stf.html> Acesso em: 31 de março de 2021.

\section{DA SILVA, José Afonso. CURSO DE DIREITO CONSTITUCIONAL POSITIVO. $37^{\mathrm{a}}$ Ed. São Paulo: MALHEIROS EDITORES LTDA, 2014.}

G1. Disponível em: < https://g1.globo.com/bemestar/coronavirus/noticia/2021/03/31/origemdo-coronavirus-de-morcegos-a-laboratorio-veja-as-conclusoes-da-investigacao-da-oms-nachina.ghtml> Acesso em: 31 de março de 2021.

G1. Disponível em: <https://g1.globo.com/bemestar/coronavirus/noticia/2021/03/31/brasilregistra-quase-4-mil-mortes-por-covid-no-dia-e-fecha-pior-mes-da-pandemia-com-668-milobitos.ghtml> Acesso em: 31 de março de 2021.

G1. Disponível em: <https://g1.globo.com/bemestar/coronavirus/noticia/2021/07/19/brasiltem-mais-de-542-mil-mortes-por-covid-na-pandemia-media-movel-de-obitos-continua-emqueda.ghtml> Acesso em: 20/07/2021.

G1. Disponível em: <https://g1.globo.com/politica/noticia/pec-do-teto-de-gastos-epromulgada-no-congresso.ghtml $>$ Acesso em: 20/07/2021.

MENDES, Gilmar; PAIVA, Paulo. Políticas Públicas no Brasil: uma abordagem institucional. Org. REIMAN, Leonardo; TONI, Jackson de. A Formação do Estado Brasileiro e o

Impacto sobre as Políticas Públicas. São Paulo: Saraiva, 2017.

NAKAMURA, André Luiz dos Santos. Direito à Saúde: judicialização, reserva do possível e mínimo existencial. In: BOLFARINI, Isabella Christina da Mota (Org.). A Efetividade dos Direitos Sociais no Brasil. Jundiaí, Paco Editorial, 2016.

OPAS - Organização Panamericana de Saúde. Disponível em: < https://www.paho.org/pt/covid19> Acesso em: 31 de março de 2021.

PODER 360. Disponível em: < https://www.poder360.com.br/governo/ministro-da-saudenelson-teich-pede-demissao-do-governo-bolsonaro//> Acesso: 30 de março de 2021.

PODER 360. Disponível em: <https://www.poder360.com.br/coronavirus/wuhan-registra-1ocaso-de-coronavirus-em-mais-de-1-mes/> Acesso: 30 de março de 2021.

REDEBRASILATUAL. Disponível em: < https://www.redebrasilatual.com.br/saude-eciencia/2020/08/brasil-115-mil-mortos-por-covid-19-e-100-dias-sem-ministro-da-saude/> Acesso 30 de março de 2021. 
REVISTA VEJA. Disponível em: <https://saude.abril.com.br/medicina/coronaviruspandemia-zoonose/> Acesso em: 29 de março de 2021.

SCHMIDT, João Pedro. Para entender as Políticas Públicas: aspectos conceituais e metodológicos. In: REIS, Jorge Renato dos; LEAL, Rogério Gesta (org.). Direitos Sociais e Políticas Públicas: desafios contemporâneos. Santa Cruz do Sul: Edunisc, 2008. p. 2207-2333.

SEN, Amartya. A Ideia de Justiça. Tradução: Denise Bottmann; Ricardo Doninelli Mendes. São Paulo: Companhia das Letras, 2011.

SEN, Amartya. Desenvolvimento como Liberdade. Tradução: Laura Teixeira Motta. São Paulo: Companhia das Letras, 2010.

SEN, Amartya. Escolha Coletiva e Bem-estar Social. Portugal: Almedina, S.A., 2017. 